\title{
On evaporation and solution as processes of diffusion
}

\section{Prof. J. Stefan}

To cite this article: Prof. J. Stefan (1890) On evaporation and solution as processes of diffusion, Philosophical Magazine Series 5, 29:176, 139-140, DOI: 10.1080/14786449008619914

To link to this article: http://dx.doi.org/10.1080/14786449008619914

曲 Published online: 14 Oct 2011.

Submit your article to this journal ¿

Џ Article views: 3

Q View related articles $\sqsubset$ 
high pressure or a vacuum. Sometimes the tube has been used for liquids which act upon the metal it is made of ; when this has been the case, a rubber tube has been threaded through the metal tubes, so as to form a protective lining.

\section{ON EVAPORATION AND SOLUTION AS PROCESSES OF DIFFUSION. BY PROF. J. STEFAN.}

In a paper published in 1873 the author described experiments which he made on evaporation from narrow tubes. Those observations led to the law that the velocity of evaporation is inversely proportional to the distance of the surface from the open end of the tube. The application of the theory of the diffusion of gases to this process led to the same law, and at the same time fumished a complete determination of the velocity of evaporation, which reuders it possible to calculate the coefficient of diffusion of vapours. These experiments have been extended by Winkelmann to several series of liquids, and have been used to determine the coefficients of diffusion of their vapours.

Similar experiments to those on evaporation may be made on the solution of solids in liquids. A rectangular prism of rock-salt was made; its height was 30 millim., and the two other dimensions were 7 and 9 millim. Glass plates were cemented by Canada balsam to the bottom and sides, so that only the top surface of the prism was free. In one of the glass plates a scale is etched. If the prism, with its top upwards, is immersed in a large vessel of water, its solution takes place from the top and the process can be observed on the seale. After $1,4,9,16$ days the solution had extended to $6 \cdot 3,12 \cdot 6,18 \cdot 8$, and 25 millim. These depths are as the square roots of the times. Hence for this process the law holds that the velocity of the solution is inversely proportional to the distance of the rock-salt surface from the open end of the prism.

If such a prism is dipped with the free surface downwards, the solution proceeds with almost uniform velocity. In one hour $17 \cdot 1$ and in $1 \frac{1}{2}$ hours $25^{\circ} 6$ millim. were dissolved. A prism of a metre in magnitude requires for its solution from upwards 70 years, and downwards $2 \frac{1}{2}$ days ; the former times increase with the magnitude is a quadratic, and the latter in simple ratio.

Experiments of the first kind may be used for investigating the diffusion of salts through their solvents. It is necessary for this to represent the process in a form which can be calculated from the theory of diffusion. This gives a new method for determining the coefficient of diffusion of salts. The method is not restricted to such bodies as can be obtained in large crystals. If a uniform mixture or a magma is formed of the powder and its saturated solution, and if a graduated tube is filled with it, the progress of the solution can be as well observed by it as with a prism of rocksalt. The law in this case is the same as in the former case, though the absolute value of the velocity with which the plave of separation of the solution and of the magma moves downwards 
is greater, and the more so the smaller the quantity of undissolved salt in the magma.

The mathematical part of the paper consists of four divisions. In the first, the equations of the theory of diffusion of gases are developed. In the second, they are applied to evaporation. The solution of this problem in the former paper was only an approximate one, yet quite sufficient for calculating the experiments. In the present paper the exact solution of the problem is communicated. Their establishment forms a fresh application of the equations which the author has developed in the theory of the formation of ice. In the third section the differential equations of the diffusion of gases are transformed into the equations which serve for calculating the diffusion of liquids. The last section contains the applications of these equations to the calculation of experiments on diffusion.-Wiener Berichte, Nov. 21, 1889.

\section{ON THE OHANGES OF TEMPERATURE RESULTING FROM THE TORSION AND DETORSION OF METAL WIRES. BY DR. A. WASSMUTH.}

In the year 1878 Sir W. Thomson (Phil. Mag. vol. v. p. 19) deduced from the mechanical theory of heat the principle that a twisted wire must become cooled when the torsion is suddenly carried further.

In the above research it is proved for iron, brass, and particularly for steel that the phenomenon in question actually occurs; and the opposite one on detorsion, that the cooling or heating increases with the angle of rotation, and that the change of temperature observed for a steel wire agrees very well with the calculated one.

In these experiments thermoelements were soldered to six steel wires connected with each other by pieces of wood, and slightly stretched horizontally, in such a manner that this wire arrangement could both be stretched and twisted. It was possible in this way to compare the very small changes of temperature on torsion and detorsion with the much larger ones due to stretching, and which indeed can be done in two ways. For the cooling $\theta$ which occurs on the torsion of a wire of length $l$ from the angle $w_{0}$ to $w_{1}$ it was calculated

$$
\mathrm{J} \frac{m}{l} c \theta=t \frac{n}{10^{4}} \frac{\mathbf{E}}{2(1+\mu)} \frac{\pi}{2} r^{4} \frac{1}{2} \frac{w_{1}^{2}-w_{0}^{2}}{l^{2}}
$$

in which $m$ was the weight, $r$ the radius, $\frac{\mathrm{E}}{2(1+\mu)}$ the modulus of torsion, $\frac{n}{10^{4}}$ its relative decrease with the absolute temperature $t$, $c$ the specific heat of the wire, and $J$ the mechanical equivalent of heat. There was thus obtained for $\theta$,

Calculated $195 \cdot 10^{-5}$ of a degree Centigrade;

Observed 191·10-5 ," ," ,

Several further experiments likewise showed agreement with what has been said.-Wiener Berichte, Nov, 7, 1889. 